Bangladesh J. Zool. 49(1): 161-167, 2021

\title{
WILDMENTOR-AN INTERACTIVE DIGITAL ENCYCLOPEDIA OF FAUNA AND FLORA OF BANGLADESH
}

\author{
Safiqul Islam*1, Shah Saquib², Alejandro Izquierdo-López ${ }^{3}$, Alexander E. \\ Hausmann ${ }^{4}$, Rukshana Sultana ${ }^{5}$, Abu N. M. Hossain ${ }^{6}$, Habibur Rahman ${ }^{7}$, Abdul \\ Alim $^{8}$, Monwar Hossain ${ }^{9}$, M Niamul Naser ${ }^{10}$, Martin Päckert ${ }^{1}$ \\ Museum of Zoology, Senckenberg Natural History Collections Dresden, \\ Königsbrücker Landstraße 159, 01109 Dresden, Germany
}

The loss of biodiversity represents a major global crisis which calls for the need of strong conservation efforts. Most of these efforts are currently being led by research groups, NGOs, educational institutions and governmental action, but in the last decades a new way of approaching conservation, namely citizen science, has become increasingly common. Citizen science has multiple nonstandardized definitions (Heigl et al. 2019), but is here understood as the process of informing the broad public about a scientific topic and make them participate in the process of data collection (Van Vliet and Moore 2016; Toms and Newson 2006). While research groups or educational institutions may have highly limited human resources, citizen science can make use of hundreds and even thousands of dedicated amateurs data collectors. Furthermore, while scientific results remain generally exclusive to the scientific community, citizen science-derived results can spread throughout the general population, educating the public (Bonney et al. 2009), generating interest for a subject (Sayer et al. 2015) and even raising awareness about global-scale issues such as human impact on the environment and its protection (Fernandez-Gimenez et al. 2008; Silvertown et al. 2013) or biodiversity-loss. This may result in long-term interest on a scientific topic across individuals and communities, even fostering crossgenerational positive conservation attitudes that regular research may not be able to achieve on its own. Mobile technologies, including APPs, have made the process of data collection easy and available to millions of people. These platforms not only create unique e-learning environments, but have also

*Author for correspondence: <safiq713@gmail.com>; ${ }^{2}$ Technische Universität München, Arcisstraße 21, 80333 München, 3Department of Ecology and Evolutionary Biology, University of Toronto, 25 Willcocks Street, Toronto, Ontario, Canada M5S 3B2, "Division of Evolutionary Biology, LudwigMaximilians-Universität München, Grosshaderner Str. 2, 82152 Planegg-Martinsried, Germany, ${ }^{5}$ Environmental Sciences, Macquarie University, Sydney, Australia, ${ }^{6}$ Bangladesh Forest Department, Dhaka, Bangladesh, ${ }^{7 D e p a r t m e n t ~ o f ~ G e o g r a p h y, ~ J a g a n n a t h ~ U n i v e r s i t y, ~ D h a k a, ~ B a n g l a d e s h, ~}$ ${ }^{8}$ Department of Zoology, Jagannath University, Dhaka, Bangladesh, ${ }^{9}$ Department of Zoology, Jahangirnagar University, Dhaka, Bangladesh, ${ }^{10 D e p a r t m e n t ~ o f ~ Z o o l o g y, ~ U n i v e r s i t y ~ o f ~ D h a k a, ~ D h a k a ~}$ 1000, Bangladesh

(C2021 Zoological Society of Bangladesh DOI: https://doi.org/10.3329/bjz.v49i1.53691 
managed to create e-communities that can work independently from external inputs. These platforms, aided by supplementary techniques, such as gamification (Saquib 2017), can improve this e-learning environment, improving the user's learning experiences and knowledge acquisition process (Hossain 2018).

The number of existing APP platforms is enormous, but only a handful of them manage to gather millions of users. To date, iNaturalist represents one of the most widely used citizen science APP, with a total of $\sim 3$ million users, of which 260,000 are active (www.inaturalist.org). iNaturalist is a biodiversity tracking system in which users are presented a catalogue of species and are encouraged to photograph, share and identify observed species in the wild. Therefore, while iNaturalist serves as an e-learning and e-community environment, it also provides species distributional data. Thus, citizen-generated data can become extremely important to monitor the abundance (Toms and Newson 2006), spread and movement (Cooper et al. 2014) of species across a region and therefore, provide valuable data to conservation efforts (Owen and Parker 2018). While APPs with an international such as iNaturalist have a broad scope that allows for a high total number of users and create thriving ecommunities, these APPs may be less successful in tracing and identifying species at a regional level and in creating strong regional e-communities when particular cultural aspects (e.g. regional language) are not considered (Storksdieck et al. 2016). These challenges are especially relevant in tropical countries, which are usually rich in both biodiversity and cultural diversity. This diversity, though, is currently affected by habitat loss and anthropogenic climate change, threatening not only habitats and biodiversity, but also damaging the natural resources many local communities depend on (Getzner and Islam 2013).

Bangladesh is located at the crossroads of two global biodiversity hotspots: the Himalayas in the North and the Indo-Burma hotspot in the East (Mittermeier et al. 2004; Marchese 2015). It harbours a few of the global priority ecoregions for conservation, such as the Sundarban Mangroves (ecoregion IM1406) or parts of the Mizoram-Manipur-Kachin Rain Forests (ecoregion IM0131) that extend southwards to the Chittagong Hills (Olsson and Dinerstein 2002). Moreover, 20 Important Bird \& Biodiversity Areas have been defined for Bangladesh covering a total land surface of 544,438 ha (BirdLife International, 2020). Thus, Bangladesh combines an enormous national biodiversity including unique environments (mangroves) with a high population density and lowlands highly endangered by sea-level rise (Ali 1996; Loucks et al. 2010). Therefore, the need for strong conservation efforts in the country is pressing. Bangladesh presents a fast-growing community of smartphones users, with $20 \%$ of its population 
currently having access to this technology, representing ca. 168 million users, and one of the countries with the largest smartphone penetration worldwide (www.newszoo.com). For these reasons, Bangladesh represents an ideal ground to make use of an iNaturalist-inspired type of APP, tailored to the local communities of Bangladesh and its flora and fauna, able to gather data on different biodiversity measurements that can promote further conservation efforts. To meet this need in Bangladesh, an international nature conservation and research group Wild Solution Foundation was founded in 2012. The mobile phone application 'Wild Mentor' is the first product and release of the Wildsolution foundation (Google play/"wildmentor"). Wild Mentor is free and user friendly and provides information and photographs about the biodiversity that surrounds the people of Bangladesh in both the local language (Bangla) and English. This APP provides quality information for the general public and it also invites users to actively contribute to this existing knowledge. It is very simple to use and requires no previous experience, bringing a new window for participatory conservation education for the broad public as well as conservationists, while creating a common sharing place for the Biodiversity conservation education in Bangladesh.

Wild Mentor has started with a straightforward objective. With the motto "get closer to the world', it asks its audience how much do we know about the flora and fauna surrounding us. Wild Mentor not only informs the users about the local animals and plants but also allows them to add information on the APP, even when offline. Knowledge is power, and keeping this in mind, the APP advocates that protecting and conserving nature and the natural resources of Bangladesh can only be achieved if the population knows about them. The ultimate goal of Wild Mentor is to mobilize communities to work towards biodiversity conservation, promoting a sustainable development that considers and prevents biodiversity loss, protecting both nature and natural resources. The benefit of the presence of this APP in an international platform will not only help the locals to know more about biodiversity, but also reach a wider international audience, such as scientists, conservationists, and wildlife enthusiasts interested in the natural resources of Bangladesh. Therefore, the researchers and the programmers of the APP are constantly trying to bring the latest information on every native animal and plant to your fingertip.

$A P P$ design and architecture: Wild Mentor's user interface and colour schemes are designed in a way that playing with the bird sounds, the species image galleries, media and share buttons, and random data cards provides the learner with a gamified experience (Fig. 1). Social and community based elearning scopes are also made available using the collaborative wall feature. 
Capturing species images and guessing their name and attributes and matching them later with AI based tags, also covers the implication of e-learning and gamification methodologies.
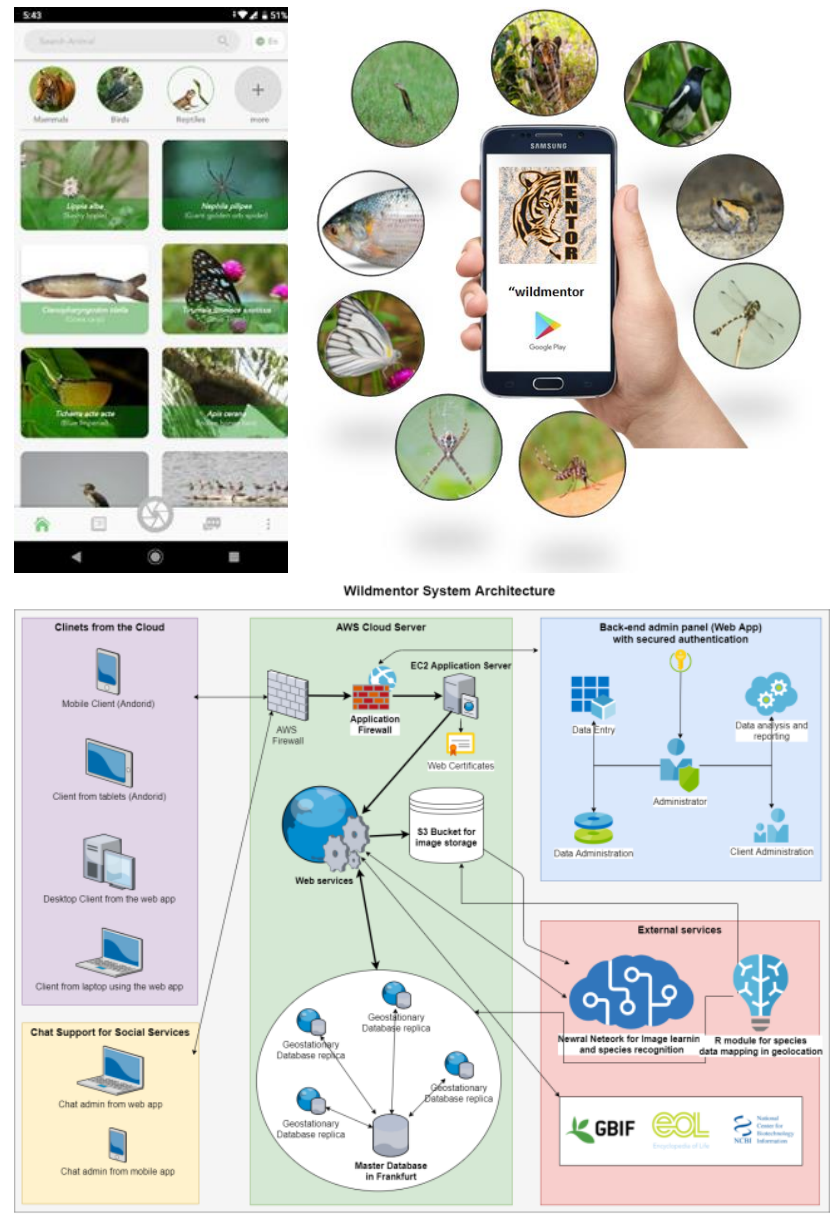

Fig. 1: Top panel: Snapshot of Wild Mentor GUI (left) and some animal groups covered by Wild Mentor (right). Bottom panel: System architecture of Wild Mentor APP (drawn with draw.io diagrams)

Wild Mentor is served from AWS. The heart of the system is its web API middleware connected to the master database and the S3 image bucket, database and storage replicas are located in different regions. They are updated and requested from client applications through REST API based web services which are deployed in EC2 AWS server and are protected by double security layers. Client applications are developed in Android and Web platforms. Its backend for user and data administration is connected to the web services as a 
separate node. The AI for species image data processing is an external service, likewise the $\mathrm{R}$ module for geo-mapping, and GBIF, EOL, NCBI connections via the middleware for data cross-matching and precision algorithms.

Conclusion: The citizen science-based APP Wild Mentor, offers a shared platform of knowledge on the natural resources of Bangladesh, open to policy makers, researchers and the layman. Since its short release, is has already achieved a significant number of users, which the Wildsolutions foundation is currently promoting even further. This innovative APP addresses the pressing need of involving local communities and empowering them with the knowledge of local flora and fauna, information which is continuously being curated and updated by a group of programmers and researchers. The ultimate goal of Wild Mentor is to educate and engage local populations in Bangladesh in conservation issues and create a long-lasting effect on the protection of the natural resources of the country.

Acknowledgements: We acknowledge the help provided by the Bangladesh forest department, with specific reference to the Chief Conservator of Forests and officials, who provide continuous support, wisdom, invaluable suggestions and logistics. We extend our gratitude to IUCN Bangladesh for their invaluable suggestions and support. We also would like to thank Zoological Society of Bangladesh (ZSB), specifically the President Prof Gulshan Ara Latifa and General secretary Dr. Tapan K Dey for their continuous support and valuable suggestions. We also extend our thanks to the University of Dhaka, Jagannath University, Chittagong University, and Jahangirnagar University. Our special thanks go to all of the students and contributors who continuously helping us with fact checking the information and provide images (www.wildmentor.org/catagory/student-researchers). We also would like to extend our thanks to the Daily Prothom Alo and electronic media, Ekattor Television, Independent TV, and Jamuna TV. Our special thanks go to Mr. Mohsin ul Hakim, Jamuna TV for unequivocal support from day one to till today. We would like to thank the Museum of Zoology, Senckenberg Natural History Collections Dresden, Königsbrücker Landstraße for their unconditional assistance throughout our journey. Finally, it's our pleasure to thank all our 'Wildmentor' users.

\section{LITERATURE CITED}

ALI, A. 1996. Vulnerability of Bangladesh to climate change and sea level rise through tropical cyclones and storm surges. In Climate change vulnerability and adaptation in Asia and the Pacific (pp. 171-179). Springer, Dordrecht. 
BONNEY, R., COOPER, C. B., DICKInSON, J., KElling, S., PHILliPS, T., ROSENBERGERG, K. V. and SHIRK, J. 2009. Citizen science: a developing tool for expanding science knowledge and scientific literacy. BioScience, 59(11), 977-984.

COOPER, C.B., SHIRK, J. and ZUCKERBERG, B. 2014. The invisible prevalence of citizen science in global research: migratory birds and climate change. PloS one, 9(9), e106508.

FERNANDEZ-GIMENEZ, M. E., BALLARD, H. L., and STURTEVANT, V. E. 2008. Adaptive management and social learning in collaborative and community-based monitoring: a study of five community-based forestry organizations in the western USA. Ecology and Society, 13(2).

GETZNER, M., and ISLAM, M. S. 2013. Natural resources, livelihoods, and reserve management: a case study from Sundarbans mangrove forests, Bangladesh. International Journal of Sustainable Development and Planning, 8(1), 75-87.

HEIGL, F., KIESLINGER, B., PAUL, K. T., UHLIK, J. and DÖRLER, D., 2019. Opinion: Toward an international definition of citizen science. Proceedings of the National Academy of Sciences, 116(17), 8089-8092.

HOSSAIN, M. 2018. Exploiting smartphones and apps for language learning: A case study with the EFL learners in a Bangladeshi university. Review of Public Administration and Management, 6(1), 1-5.

LOUCKS, C., BARBER-MEYER, S., HOSSAIN, M. A. A., BARLOW, A., and CHOWDHURY, R. M. 2010. Sea level rise and tigers: predicted impacts to Bangladesh's Sundarbans mangroves. Climatic Change, 98(1-2), 291.

MARCHESE, C. 2015. Biodiversity hotspots: A shortcut for a more complicated concept. Global Ecology and Conservation, 3, 297-309.

MITTERMEIER, R.A., ROBLES GIL, P., HOFFMANN, M., PILGRIM, J. D. BROOKS, T. M., MITTERMEIER, C. G., and FONSECA, G. A. B. da. 2004. Hotspots Revisited: Earth's Biologically Richest and Most Endangered Ecoregions. CEMEX, Mexico City.

OLSSON, D. M., and DINERSTEIN, E. 2002. The Global 2000: Priority Ecoregions for Global Conservation. Annals of the Missouri Botanical Garden, 89(2), 199-224.

OWEN, R. P., and PARKER, A. J. 2018. Citizen science in environmental protection agencies. In HECKER, S., HAKLAY, M., BOWSER, A., MAKUCH, Z., VOGEL, J. and BONN, A. 2018. Citizen Science: Innovation in Open Science, Society and Policy. (pp 284-300). UCL Press, London.

SAQUIB, S. 2017. Gamification in the eLearning context, TU Munich, Germany. DOI: 10.13140/RG.2.2.30217.34402

SAYER, J., MARGULES, C., BOHNET, I., BOEDHIHARTONO, A., PIERCE, R., DALE, A., and ANDREWS, K. 2015. The role of citizen science in landscape and seascape approaches to integrating conservation and development. Land, 4(4), 1200-1212.

SILVERTOWN, J., BUESCHING, C.D., JACOBSON, S.K., and REBELO, T. 2013. Citizen science and nature conservation. Key topics in conservation biology, 2(1), 127-142. 
STORKSDIECK, M., SHIRK, J. L., CAPPADONNA, J. L., DOMROESE, M., GÖBEL, C., HAKLAY, M., and VOHLAND, K. 2016. Associations for citizen science: regional knowledge, global collaboration. Citizen Science: Theory and Practice, 1(2), 10.

TOMS, M. P. and NEWSON, S. E. 2006. Volunteer surveys as a means of inferring trends in garden mammal populations. Mammal Review, 36(4), 309-317.

VAN VLIET, K., and MOORE, C. 2016. Citizen science initiatives: engaging the public and demystifying science. Journal of microbiology \& biology education, 17(1), 13.

BirdLife International (2020). Country profile: Bangladesh. Available from http://www.birdlife.org/datazone/country/bangladesh. Checked: 2020-11-16

iNaturalist. Available from https://www.inaturalist.org. Checked: 2020-11

Newzoo. Available from https://newzoo.com/insights/trend-reports/newzoo-global-mobile-marketreport-2019-light-ve

(Manuscript received on 20 March, 2020 revised on 9 April, 2021) 